\title{
ENTRE LA TEORÍA Y LA TÁCTICA. RESEÑA DE ANDREA DONOFRIO, ERASE UNA VEZ EL EUROCOMUNISMO. LAS RAZONES DE UN FRACASO
}

\section{BETWEEN THEORY AND TACTICS. REVIEW OF ANDREA DONOFRIO, ERASE UNA VEZ EL EUROCOMUNISMO. LAS RAZONES DE UN FRACASO}

\author{
Juan Francisco Fuentes Aragonés \\ Univesidad Complutense de Madrid
}

\begin{abstract}
Recensión de / Review of: Andrea Donofrio: Érase una vez el eurocomunismo. Las razones de un fracaso, Ed. Tecnos, Madrid, 2018, 434 páginas
\end{abstract}

Palabras clave: eurocomunismo, guerra fria, siglo XX

Key Words: eurocomunism, cold war, 20 thCentury

El fenómeno del eurocomunismo, surgido de una izquierda que ya no existe, produce hoy en día una mezcla de perplejidad y añoranza. Pertenece a un tiempo no tan lejano, pero inserto en un contexto histórico desaparecido tras la caída del muro de Berlin y el fin de la Guerra Fria y todo lo que ella comportaba: un mundo bipolar, regido por unas reglas del juego cínicas pero efectivas, respetadas en general por las grandes potencias y basadas en el principio de la destrucción mutua asegurada. Esa sensación de lejanía de aquella época y aquella izquierda explica el bello título, como de cuento de hadas, que el historiador y politólogo Andrea Donofrio ha elegido para este magnífico libro sobre el eurocomunismo. En una Europa en la que se tiende, por un lado, a un populismo post-ideológico y, por otro, a una radicalización política tanto de la derecha como de la izquierda, resulta dificil entender el eurocomunismo en lo que tuvo de racionalización del viejo discurso comunista $\mathrm{y}$ de giro hacia posiciones templadas, casi socialdemócratas, que poco antes hubieran parecido heréticas. Incluso en los años setenta, cuando esta versión moderada y pragmática del marxismoleninismo se impuso entre los principales partidos occidentales, no faltaron los guardianes de la ortodoxia que la consideraran una aberración ideológica y una traición política.

El libro de Donofrio entra en la breve historia del eurocomunismo -menos de una década, entre mediados de los años 70 y principios de los 80- después de abordar la doble cuestión de sus fuentes doctrinales y de sus antecedentes históricos. Es una parte fundamental de su estudio, que ocupa más de un tercio del libro; y es lógico que así sea, en primer lugar, porque sólo conociendo a fondo sus raíces intelectuales se podía definir con cierta precisión su perfil ideológico, y, en segundo lugar, porque los críticos del eurocomunismo, sobre todo aquellos que se situaban en el campo de la ortodoxia comunista, pusieron siempre en duda que tras el giro eurocomunista de los partidos de Europa occidental hubiera un verdadero corpus teórico. Para ellos, y en general para sus detractores de toda 
condición, el eurocomunismo era un puro oportunismo político. Puede que no les faltara razón. En todo caso, oportunista o no, la opción eurocomunista no fue el resultado de una reflexión teórica sobre la verdadera esencia del comunismo, sino de la necesidad de acomodar la estrategia de ciertos partidos comunistas aquellos que contaban con una mayor implantación en los países de Europa occidental- a sus objetivos políticos más inmediatos: en Italia, ganar las elecciones y obtener una mayoría suficiente para gobernar; en Francia, disputar al nuevo Partido Socialista la hegemonía de la izquierda, y en España, recuperar la democracia e influir decisivamente en el nuevo juego político. No fue, pues, un cambio de paradigma teórico el que llevó a elaborar una nueva estrategia política, sino esta última la que impulsó una reflexión sobre las fuentes doctrinales del comunismo que derivó en una suerte de tradición inventada.

De todo ello se ocupa Andrea Donofrio en ese primer tercio del libro, en el que, por un lado, investiga los orígenes del propio concepto de eurocomunismo, rectificando la habitual atribución al socialista italiano Lelio Basso, y, por otro, valora sus referentes ideológicos reconocidos como tales, entre ellos, y de forma muy destacada, Rosa Luxemburgo y Antonio Gramsci. Donofrio establece una precisa genealogía de esa particular concepción del comunismo contraria a la ortodoxia impuesta en su dia por Stalin e incluso, antes, por Lenin. ¿Cabia en esa relectura del comunismo el concepto, típicamente leninista, de dictadura del proletariado? El autor recuerda que el VIII Congreso del PCE, celebrado en 1972, fue el último en el que los comunistas españoles utilizaron la expresión y que el propio Carrillo defendió su supresión en coherencia con la lucha por la democracia que abanderaba el partido. "Dictadura ni la del proletariado", llegó a decir para escándalo de algunos de los suyos. La cuestión fue más espinosa en el caso del PCF -tradicionalmente considerado el más renuente a asumir el eurocomunismo con todas sus consecuencia-, mientras que el PCI podia, con más razón que nadie, acudir a Gramsci para reformular el concepto y vaciarlo de sus ingredientes más indeseables, jugando con la noción de "hegemonía" para tender un puente entre la tradición leninista y la realidad democrática en la que se movía el PCI de los años setenta.

El libro bascula continuamente entre las ideas y los hechos, entre un acervo teórico que el autor conoce muy bien y unos acontecimientos históricos que marcaron la lenta transición del comunismo occidental desde sus postulados estalinistas de los años cincuenta a su compromiso con la democracia en los setenta. Como dijeron en su día E. Nassi y M. Cesarini, el eurocomunismo fue el resultado de una "dramática serie de estados de necesidad" que van desde la desestalinización a la Primavera de Praga en 1968, principal desencadenante del giro hacia una creciente independencia de los partidos occidentales respecto a la linea marcada por la URSS. Habria que añadir el golpe de Estado de Pinochet en Chile en septiembre de 1973, que reforzó, sobre todo en el PCI y en el PCE, el convencimiento de que sólo un comunismo moderado y prudente, dispuesto a entenderse con los sectores centristas de la burguesía, sería capaz de evitar una involución cruenta, como la que acabó con el gobierno de Allende, en la lucha por una democracia avanzada.

El eurocomunismo nació formalmente en 1975, después de una gestación de varios años y de continuos desencuentros con el líder soviético Leónidas Breznev. A partir de la puesta en marcha del proyecto eurocomunista se producirá un rápido proceso de convergencia entre los tres grandes partidos -el PCI, el PCF y el 
PCE-, escenificado en las grandes "cumbres" de mediados de los setenta. E1 impacto político y mediático del fenómeno fue indudable. Quedaba por ver hasta qué punto la apuesta estratégica de sus dirigentes obtenía el respaldo de la militancia y del electorado potencialmente afin. Tiene especial interés por ello la evolución electoral de los tres partidos en contextos políticos relativamente distintos, porque el éxito o fracaso del eurocomunismo se mediría finalmente en las urnas. Tal fue el reto que asumió el PCI a mediados de los setenta, erigido en punta de lanza de un ascenso electoral que debía llevarle más temprano que tarde al poder y arrastrar a sus partidos hermanos a posiciones de influencia politica en sus respectivos países. Como recuerda Donofrio, el punto de inflexión se sitúa en 1976, cuando el PCI, que había quedado muy cerca de la Democracia Cristiana en las elecciones administrativas celebradas el año anterior, afrontó las legislativas con serias opciones de conseguir el ansiado sorpasso -superar a la DC- y formar gobierno. Aquello fue el principio del fin. La moderación de que venía haciendo gala el partido -es decir, la puesta en práctica del eurocomunismo- y la carismática personalidad de su líder, Enrico Berlinguer, le valieron un excelente resultado $(34,4 \%$ de los votos), pero todavía por debajo de la DC (38,7\%) e insuficiente por tanto para alterar el statu quo. Tras aquellas elecciones, una larga y compleja serie de circunstancias señaladas por el autor, desde el agravamiento de la crisis económica hasta el asesinato de Aldo Moro en 1978, bloquearon la posibilidad del compromiso histórico preconizado por el partido y provocaron el desconcierto y la frustración de la militancia, cada vez más alejada de los postulados eurocomunistas. La pregunta que se hacian muchos comunistas de a pie y no pocos intelectuales del partido era para qué servía una estrategia politica llena de renuncias y sacrificios si a fin de cuentas el PCI seguía en la oposición y el sorpasso quedaba cada vez más lejos.

La cuestión explícitamente planteada en el subtítulo del libro -Las razones de un fracaso- obtiene cumplida respuesta en el penúltimo capítulo - "E1 desencanto: las razones del fracaso"- y, en realidad, aunque de forma menos sistemática, a lo largo de toda la obra. “¿Fracasó porque duró poco o duró poco por su fracaso?", se pregunta Donofrio. Las respuestas a esta cuestión tienen inevitablemente un cierto aire tautológico. No es incapacidad para ofrecer argumentos convincentes que expliquen la sensación de derrota que el eurocomunismo dejó entre los suyos. Es que la principal justificación de esta audaz ruptura con la ortodoxia que fue el eurocomunismo era un éxito electoral que finalmente no se produjo, y no se produjo -podrá argüirse- por la inconsistencia doctrinal y el oportunismo politico de un proyecto concebido principalmente como una "panacea táctica", en expresión del autor. De ahí, como él mismo señala, la ambigüedad del proyecto de sociedad que se defendía para el día después de la victoria. Por eso, una vez demostrada su ineficiencia como panacea en el terreno electoral, el eurocomunismo perdió buena parte de su justificación y quedó a merced de sus detractores, aquellos que desde el principio vieron en él un revisionismo vergonzante, un keynesianismo de izquierdas difícil de distinguir de la vieja socialdemocracia, verdadera bestia negra del comunismo a lo largo de todo el siglo XX. Y en el caso del PCF, casi ni eso: su fuerte componente nacionalista, compatible con una buena relación con Moscú, hacía del comunismo francés eso que un autor ha llamado un "gaullismo rojo" con ciertos tintes populistas, lo que explicaría tal vez adónde han ido a parar muchos de los votos del antiguo PCF. 
El libro se beneficia de la doble condición del autor de historiador y politólogo, aunque su formación académica en Italia y España le sitúe más en el ámbito de la ciencia política que en el de la historia contemporánea. Por eso mismo sorprende una cierta desatención al estudiar la evolución electoral de los tres grandes partidos eurocomunistas, sobre todo del PCF y del PCE, merecedora de un análisis más detenido y circunspecto. En el caso de este último partido, no hay referencia a las elecciones generales de 1979, que marcaron el techo electoral del PCE en toda su historia y que paradójicamente desataron un proceso autodestructivo de consecuencias irreparables. Es verdad, como dice Donofrio, que el descalabro del PCE en las elecciones de 1982 abocó al partido prácticamente a su desaparición, al menos como marca electoral. Pero el proceso comprendido entre 1979 y 1982 y el baño de realidad que supusieron las elecciones del 79, pese a mejorar levemente el resultado de 1977, merecían una reflexión de mayor calado sobre los problemas del comunismo español, del que afirma Donofrio que era probablemente el más eurocomunista de los grandes partidos occidentales. Volvemos asi a la interpretación del fenómeno como resultado de un estado de necesidad que en ningún otro partido se daba con tanta intensidad como en el que dirigia Santiago Carrillo. El hecho es que, como se dice al final del libro, el eurocomunismo representó más el final de una época que el principio de algo que nunca se produjo.

Érase una vez el eurocomunismo indaga en uno de los fenómenos más originales y llamativos del final de la Guerra Fría y contribuye a explicar el hundimiento del comunismo como alternativa global al capitalismo. Se puede decir que el eurocomunismo anticipa la perestroika soviética imprimiendo un giro audaz a la concepción del comunismo en un intento de reconciliarlo con la democracia liberal y la economía de mercado. Su fracaso anticipó también el de la perestroika. Desde este punto de vista, el libro de Andrea Donofrio es mucho más que un brillante ejercicio de historia politica comparada o una investigación sobre las raíces teóricas del eurocomunismo, con ser cuestiones de gran trascendencia. Es también una relevante aportación al conocimiento de las claves más complejas del auge y ocaso del comunismo como una de las principales criaturas del siglo $\mathrm{XX}$.

Enviado el (Submission Date): 19/04/2019

Aceptado el (Acceptance Date): 10/05/2019 